(n)

\title{
Antenatal/early postnatal hypothyroidism alters arterial tone regulation in 2-week-old rats
}

\author{
Svetlana I Sofronova1,2,*, Dina K Gaynullina1,2,3,*, Anastasia A Shvetsova1,2, \\ Anna A Borzykh', Ekaterina K Selivanova1,2, Daria S Kostyunina',2, Anna P Sharova1, \\ Andrey A Martyanovi,2 and Olga S Tarasova ${ }^{1,2}$
}

${ }^{1}$ Institute for Biomedical Problems, Russian Academy of Sciences, Moscow, Russia ${ }^{2}$ Faculty of Biology, M.V. Lomonosov Moscow State University, Moscow, Russia 3Department of Physiology, Russian National Research Medical University, Moscow, Russia *(S I Sofronova and D K Gaynullina contributed equally to this work)
Correspondence should be addressed to S I Sofronova Email

sofronova.mailbox@gmail.com

\begin{abstract}
The mechanisms of vascular alterations resulting from early thyroid hormones deficiency are poorly understood. We tested the hypothesis that antenatal/early postnatal hypothyroidism would alter the activity of endothelial NO pathway and Rho-kinase pathway, which are specific for developing vasculature. Dams were treated with propylthiouracil (PTU, 7 ppm) in drinking water during gestation and 2 weeks after delivery, and their progeny had normal body weight but markedly reduced blood levels of thyroid hormones (ELISA). Small arteries from 2-week-old male pups were studied using wire myography, qPCR and Western blotting. Mesenteric arteries of PTU pups, compared to controls, demonstrated smaller maximum response to $\alpha_{1}$-adrenergic agonist methoxamine and reduced mRNA contents of smooth muscle differentiation markers $\alpha$-actin and SERCA2A. Inhibition of basal NO synthesis by L-NNA led to tonic contraction of mesenteric arteries and augmented their contractile responses to methoxamine; both L-NNA effects were impaired in PTU pups. PTU pups demonstrated lower blood level of NO metabolites compared to control group (Griess reaction). Rho-kinase inhibitor Y27632 strongly reduced mesenteric arteries responses to methoxamine in PTU pups, that was accompanied by elevated Rho-kinase content in their arteries in comparison to control ones. Unlike mesenteric, saphenous arteries of PTU pups, compared to controls, had no changes in $\alpha$-actin and SERCA2A contents and in responses to L-NNA and Y27632. In conclusion, thyroid hormones deficiency suppresses the anticontractile effect of NO and potentiates the procontractile Rho-kinase effects in mesenteric arteries of 2-weekold pups. Such alterations disturb perinatal cardiovascular homeostasis and might lead to cardiovascular pathologies in adulthood.
\end{abstract}
Key Words
- actin isoforms
- deiodinase 2
- early postnatal development
- eNOS
- myosin isoforms
- Rho-kinase
- sercaza
- small arteries
- thyroid hormones

\section{Introduction}

Thyroid hormones are well-known modulators of metabolic processes in the adult organism (Mullur et al. 2014). The thyroid system disruptions known as hypo- or hyperthyroidism greatly affect almost every organ function, and, among others, the vascular system (Vargas et al. 2006, Iervasi \& Nicolini 2013). 
Moreover, thyroid hormones are key regulators of the developmental processes. In particular, their deficiency during early stages of ontogenesis (prenatal and early postnatal) has crucial effects and leads to the improper development of the individual (Forhead \& Fowden 2014). This can occur during pregnancy, when the mother might suffer from hypothyroidism, which will have adverse effects on her progeny (StagnaroGreen 2015). Of note, up to $15 \%$ of all pregnancies are accompanied by the overt or subclinical hypothyroidism (Stagnaro-Green 2015). Our recent findings show that antenatal/early postnatal hypothyroidism significantly alters the regulation of coronary circulation by abolishing the anticontractile effect of nitric oxide (NO) (Gaynullina et al. 2017). Developmental effects of thyroid hormones on cardiovascular system are mediated by both genomic as well as nongenomic mechanisms, which may overlap at the nuclear level (Ojamaa 2010, Davis et al. 2015).

Human thyroid deficiency in neonatal age is associated with poor peripheral circulation and impaired reflex control of vascular tone (Bower 1957). In addition, an increased intima-media thickness was reported in hypothyroid newborns as a risk factor for early cardiovascular disease (Akin et al. 2013). Antenatal thyroidectomy in lambs was associated with reduced blood flow to heart (Portman et al. 2000) and peripheral organs (Breall et al. 1984). However, hypothyroid-associated vascular alterations during early postnatal period are poorly understood and their mechanisms are not explored yet (Portman 2008).

Vasoregulatory phenotype of the developing organism is significantly different from that in adults. Smooth muscle in developing vessels has a strongly augmented $\mathrm{Ca}^{2+}$ sensitivity of contractile apparatus, which compensates for the deficiency of $\mathrm{Ca}^{2+}$-dependent control of smooth muscle contraction (Sandoval et al. 2007, Puzdrova et al. 2014). Such $\mathrm{Ca}^{2+-s e n s i t i z a t i o n ~}$ is due to enhanced contribution of Rho-kinase in contractile responses of arteries during early postnatal period (Akopov et al. 1998, Mochalov et al. 2008). Another important vasomotor feature of the developing vasculature is NO-mediated anticontractile effect of the endothelium that is prominent in early postnatal period and gradually decreases with maturation (Gaynullina et al. 2013, Sofronova et al. 2016). These two mechanisms are considered to be important for the regulation of arterial tone and blood pressure level in immature vascular system.
We hypothesized that the deficiency of thyroid hormones will affect the regulation of contractile responses in arteries of young rats by alteration of specific for young vasculature NO and Rho-kinase pathways. To test this hypothesis, we used the model of antenatal/ early postnatal hypothyroidism: a condition where thyroid hormones synthesis is suppressed in maternal organism starting from the first day of pregnancy till 2 weeks after delivery. The vascular consequences of antenatal/early postnatal hypothyroidism were studied in 2-week-old male offspring.

\section{Methods}

\section{Animals}

Adult female and male Wistar rats weighing 250-300g were obtained from the vivarium of the Institute of General Pathology and Pathophysiology (Moscow, Russia) and bred in the vivarium of Biological Faculty, Moscow State University. The investigation conforms to the Guide for the Care and Use of Laboratory Animals published by the US National Institutes of Health (NIH Publication No. 85-23, revised 1996), Russian national guides and regulations at the Moscow State University.

\section{The model of antenatal/early postnatal hypothyroidism}

Female rats were housed with males for one night, and at 8:00 h the next morning, the pregnancy was confirmed by the presence of sperm in the vaginal smear; this day was considered as gestation day 1 . Then pregnant dams were randomly divided into two groups. To induce hypothyroidism, the dams were treated with 6-propyl-2thiouracil (PTU, Sigma) in the drinking water from the first gestational day until 2 weeks after delivery (PTU group). The concentration of PTU was chosen to be $7 \mathrm{ppm}(7 \mu \mathrm{g} / \mathrm{mL})$. Control group of dams consumed water without PTU.

Vascular effects of antenatal/early postnatal hypothyroidism were studied in the progeny of 6 PTUtreated and 6 control dams. The litters were culled to 8 pups on the first day after delivery. Throughout the whole period of treatment pregnant dams, and later, dams with offspring were regularly weighted; their water intake was measured as well. Duration of pregnancy, number of pups per litter in control and PTU groups were also recorded. Fourteen- to fifteen-day-old male pups from each group

Published by Bioscientifica Ltd. 
of dams (control or PTU-treated) were evenly distributed into subgroups, which were subsequently used for blood sampling and isolation of saphenous arteries and small mesenteric arteries (2-3-order branches of the superior mesenteric artery).

\section{The analysis of blood samples}

Serum blood parameters were tested in: (i) virgin control females; (ii) pregnant control and PTU females on gestation day 21 (G21); (iii) control and PTU dams on postpartum day 14-15 (P14) and (iv) 14- to 15-dayold male pups. Blood was collected after decapitation and incubated at $37^{\circ} \mathrm{C}$ for $30 \mathrm{~min}$ followed by $30 \mathrm{~min}$ at $4^{\circ} \mathrm{C}$. After that blood samples were centrifuged for $15 \mathrm{~min}$ at $4300 \mathrm{~g}$, serum was frozen at $-20^{\circ} \mathrm{C}$ and kept till further analysis. The levels of hormones were measured by ELISA. For total $T_{4}$, total $T_{3}$, free $\mathrm{T}_{3}$, free $\mathrm{T}_{4}$ and progesterone commercial kits from Immunotek (Moscow, Russia) were used. The intraassay coefficients of variability (CV) were $2.7 \%$ for total $\mathrm{T}_{4}, 3.3 \%$ for free $\mathrm{T}_{4}, 7.5 \%$ for total $\mathrm{T}_{3}, 13.5 \%$ for free $\mathrm{T}_{3}$ and $7.9 \%$ for progesterone. For rat thyroidstimulating hormone (TSH), we used a commercial kit from Demeditec Diagnostics GmBH (Germany), intra-assay $\mathrm{CV}$, as reported by the manufacturer is less than 5\%. For estradiol, we used a commercial kit from DRG Instruments $\mathrm{GmBH}$ (Germany), intra-assay CV was $14.6 \%$.

Nitric oxide metabolites (nitrate and nitrite) concentration in blood was evaluated by Griess method after reduction of nitrate by vanadium (III) (Sofronova et al. 2015), intra-assay CV was 3.7\%. Total cholesterol concentration was measured using enzymatic colorimetric method with commercial kit from Vital Development Corporation (St.-Petersburg, Russia), intra-assay CV was $3.7 \%$. The glucose level was measured using test strips from Diacont (Moscow, Russia).

\section{qPCR}

mRNA contents of deiodinase 1 (D1), deiodinase 2 (D2), deiodinase 3 (D3), thyroid hormone receptor $\alpha_{1}$ $\left(\mathrm{TR} \alpha_{1}\right), \alpha$-actin, $\beta$-actin, SM22 $\alpha$, smooth muscle myosin heavy chains (SM-MHC), non-muscle myosin heavy chains (NM-MHC), SERCA2A, phospholamban (PLB), L-type $\mathrm{Ca}^{2+}$ channel (LTCC) and inducible NO-synthase (iNOS) in saphenous and mesenteric arteries of 2-weekold rats were measured by qPCR as previously described (Sofronova et al. 2016). In brief, two saphenous arteries or six mesenteric arteries from one rat were pooled in one sample. The arteries were fixed in RNA-later (Qiagen) and kept at $-80^{\circ} \mathrm{C}$. RNA was extracted using RNeasy Mini Kit (Qiagen) and treated with DNase I (Fermentas, 1000U/mL). cDNA was synthesized using reverse transcription kit MMLV RT (Evrogen, Russia) and stored at $-80^{\circ} \mathrm{C}$ pending further processing. qPCR was run in Rotor Gene 6000 (Corbett Research, Australia) using SYBR Green I and Taq-polymerase Master Mix (Syntol or Evrogen, Russia). The primers were obtained from Evrogen (Moscow, Russia), and their sequences are presented in Table 1. Amplification protocol included 10 -min heating at $95^{\circ} \mathrm{C}$, followed by 40 cycles, consisting of three phases: $30 \mathrm{~s}$ at $95^{\circ} \mathrm{C}, 30 \mathrm{~s}$ at $60^{\circ} \mathrm{C}$ and $60 \mathrm{~s}$ at $72^{\circ} \mathrm{C}$ and final incubation at $72^{\circ} \mathrm{C}$ for $10 \mathrm{~min}$.

qPCR experiments were analyzed in Rotor Gene 6000 Software. Gene expression levels were calculated as

Table 1 Gene-specific primers used in qPCR.

\begin{tabular}{lll} 
Target & & Gene name \\
\cline { 1 - 1 } TR $\alpha 1$ & & Thra \\
D1 & Dio1 \\
D2 & Dio2 \\
D3 & Dio3 \\
$\alpha$-actin & Acta2 \\
$\beta$-actin & Actb \\
SM22 $\alpha$ & & Tagln \\
SM-MHC & Myh11 \\
NM-MHC & Myh10 \\
SERCA2A & Atp2a2 \\
PLB & Pln \\
LTCC & Cacna1c \\
iNOS & Nos2 \\
GAPDH & Gapdh \\
18S & Rn18s \\
\end{tabular}

\begin{tabular}{l} 
Forward primer $\left(5^{\prime}-3^{\prime}\right)$ \\
\hline TGCCCTTACTCACCCCTACA \\
TCTGGGATTTCATTCAAGGC \\
CTTTGAACGTGTGTGCATCGT \\
GCTCGAACTGGCAACTTTGTC \\
CCTGACCCTGAAGTATCCGA \\
CAGGGTGTGATGGTGGGTATGG \\
TTCTGCCTCAACATGGCCAAC \\
TTTGCCATTGAGGCCTTAG \\
TGAGAAGCCGCCACACATC \\
CGAGTTGAACCTTCCCACAA \\
AACTAAACAGTCTGCATTGTGACGA \\
CATCTCCATCACCTTCTTCC \\
AGGCTTGGGTCTTGTTAGCCTAGT \\
CACCAGCATCACCCCATTT \\
CACGGGTGACGGGGAATCAG
\end{tabular}

Reverse primer $\left(5^{\prime}-3^{\prime}\right)$

AAGCCAAGCCAAGCTGTCCT

TAGAGCCTCTCAGGCAGAGC TCTCCAGCCAACTTCGGACTT GTGAGATGCTGGCGACTTATTG

CATCTCCAGAGTCCAGCACA

AGTTGGTGACAATGCCGTGTTC

CACCTTCACTGGCTTGGATC

GTTCACACGGCTGAGAATCCA

CACCCGTGCAAAGAATCGA

AGGAGATGAGGTAGCGGATGAA

GCCGAGCGAGTAAGGTATTGGA

AAATACCTGCATCCCAATCAC

ATTCTGTGCAGTCCCAGTGAGGAA

CCATCAAGGACCCCTTCATT

CGGGTCGGGAGTGGGTAATTTG

\begin{tabular}{c} 
Product size, bp \\
\hline 133 \\
331 \\
100 \\
105 \\
281 \\
115 \\
249 \\
69 \\
92 \\
268 \\
178 \\
181 \\
270 \\
157 \\
105
\end{tabular}

http://joe.endocrinology-journals.org DOI: 10.1530/JOE-17-0225
๑) 2017 Society for Endocrinology Printed in Great Britain 
$1 / E^{\wedge} C_{\mathrm{T}}$, where $E$ is the primer efficiency, and $C_{\mathrm{T}}$ is the cycle number on which the curve for product accumulation is crossing the fluorescence detection threshold. These values were normalized to the geometric mean of the two housekeeping genes (GAPDH and 18S rRNA) in the same sample.

\section{Experiments on isolated arteries}

Arterial segments (2-mm-long) were mounted in wire myograph (DMT, Denmark, models 410A and 620) for isometric recording of their contractile force. Tissue bath was filled with salt solution (in mmol/L): $120 \mathrm{NaCl}, 26$ $\mathrm{NaHCO}_{3}, 4.5 \mathrm{KCl}, 1.2 \mathrm{NaH}_{2} \mathrm{PO}_{4}, 1.0 \mathrm{MgSO}_{4}, 1.6 \mathrm{CaCl}_{2}$, 5.5 D-glucose, 0.025 EDTA, 5 HEPES, continuously bubbled with $5 \% \mathrm{CO}_{2}$ in $95 \% \mathrm{O}_{2}$ and kept at $37^{\circ} \mathrm{C}$. The segments were stretched to $0.9 \mathrm{~d}_{100}$, where $\mathrm{d}_{100}$ is the inner diameter which the vessel with relaxed smooth muscle would have if rounded and subjected to the transmural pressure of $100 \mathrm{mmHg}$ (Mulvany \& Halpern 1977). Then, a standard activation procedure was performed (Sofronova et al. 2015).

In each experiment, we used two segments cut from the same rat artery. The contractile responses to methoxamine (MX, $\alpha_{1}$-adrenoceptor agonist, in the range from $0.01 \mu \mathrm{mol} / \mathrm{L}$ to $100 \mu \mathrm{mol} / \mathrm{L}$, Sigma) were studied. The protocol was analogous to previously described in details (Sofronova et al. 2015). The first cumulative concentration-response relationships to MX were similar for two studied segments. To evaluate the anticontractile effect of NO, we compared the second concentrationresponse relationships to $\mathrm{MX}$ after 20-min incubation of one preparation with $\mathrm{N}^{\omega}$-nitro-L-arginine (L-NNA, $100 \mu \mathrm{mol} / \mathrm{L}$, inhibitor of NO-synthase (NOS), Alexis Biochemicals) and another one with N-nitro-D-arginine (D-NNA, $100 \mu \mathrm{mol} / \mathrm{L}$, inactive analogue of L-NNA, Alexis Biochemicals). To evaluate the contribution of Rhokinase in vascular contraction, Rho-kinase inhibitor Y27632 ((R)-(+)-trans- $N$-(4-pyridyl)-4-(1-aminoethyl)cyclohexanecarboxamide, $3 \mu \mathrm{mol} / \mathrm{L}$, Calbiochem) or equivalent volume of vehicle $\left(\mathrm{H}_{2} \mathrm{O}\right)$ were added $20 \mathrm{~min}$ prior to the second concentration-response relationship to MX. In addition, we studied the responsiveness of endothelium-denuded preparations to $\mathrm{NO}$ donor $\mathrm{DEA} / \mathrm{NO}$ (in the range from $0.001 \mu \mathrm{mol} / \mathrm{L}$ to $10 \mu \mathrm{mol} / \mathrm{L}$, Alexis Biochemicals) after precontraction with MX up to $70-80 \%$ from the maximum active force. In these experiments, the endothelium was mechanically removed with a rat whisker (Sofronova et al. 2015).
The wire myograph experiments were analyzed as described earlier (Sofronova et al. 2015). The maximum value of active force in the first concentration-response relationship (measured from the fully relaxed state) was used for normalization of active force values recorded in the respective second concentration-response relationship. Additionally, the $\mathrm{pD}_{2}$ (the negative logarithm of the $\mathrm{EC}_{50}$ value) was calculated in GraphPad Prism 6.0 Software. The responses to DEA/NO were calculated in percent of the precontraction level.

\section{Western blotting}

For one sample, we used 2 saphenous or 6 mesenteric arteries from one 2-week-old rat. The arteries were isolated, quickly frozen in liquid $\mathrm{N}_{2}$ and kept at $-80^{\circ} \mathrm{C}$ pending further analysis. Samples were homogenized in SDS-buffer (0.0625 mol/L Tris-HCl (pH 6.8), 2.5\% SDS, $10 \%$ water-free glycerin, $2.47 \%$ dithiothreitol, $0.002 \%$ bromophenol blue) supplemented with protease inhibitors (aprotinin $50 \mathrm{mg} / \mathrm{mL}$, leupeptin $100 \mathrm{mg} / \mathrm{mL}$, pepstatin $30 \mathrm{mg} / \mathrm{mL}$ ), centrifuged at $14,000 \boldsymbol{g}$ for $2 \mathrm{~min}$ and heated at $99^{\circ} \mathrm{C}$ for $2 \mathrm{~min}$; supernatant was kept at $-20^{\circ} \mathrm{C}$. Proteins were separated by SDS-PAGE and transferred to nitrocellulose membrane (Santa Cruz, USA) using Trans-Blot Turbo transfer system (BioRad). The transfer was visualized with Ponceau S stain and the membrane was cut in two parts at the level of $70 \mathrm{kDa}$ protein marker (Thermo Scientific). Both parts were blocked with 5\% nonfat milk (Applichem, Germany) in TBS $(20 \mathrm{mmol} / \mathrm{L}$ Tris- $\mathrm{HCl}, \mathrm{pH} 7.6 ; 150 \mathrm{mmol} / \mathrm{L} \mathrm{NaCl})$ with $0.1 \%$ Tween 20 (TBSt). Then, the lower part of the membrane was incubated overnight with antibodies against GAPDH (Abcam, 1:2000 in TBSt with 5\% milk, Sigma). The upper part was incubated overnight with antibodies against endothelial NOS (eNOS or NOS3, BD Transduction, 1:2000, in 5\% milk) or Rho-kinase II (ROCK2, Millipore, 1:200 in TBSt). Afterwards, the membranes were incubated with appropriate secondary antibodies: anti-mouse (Cell Signaling, 1:5000 in 5\% milk) or anti-rabbit (Cell Signaling, 1:5000 in 5\% milk) for $1 \mathrm{~h}$ and visualized with Super Signal West Dura Substrate (Thermo Scientific) using ChemiDoc (BioRad).

Western blotting experiments were analyzed in ImageLab Software (BioRad). Protein of interest to GAPDH ratio was identified in each sample, and then the average ratio in the control group was taken as $100 \%$. 
Table 2 Blood serum levels of hormones and energy substrates in non-pregnant and pregnant control and PTU-treated female rats.

\begin{tabular}{|c|c|}
\hline Parameters & Virgin control \\
\hline Total $\mathrm{T}_{4}(\mathrm{nmol} / \mathrm{L}) n=6 ; 9 ; 5 ; 12 ; 5$ & $97.6 \pm 4.5$ \\
\hline Free $\mathrm{T}_{3}(\mathrm{pmol} / \mathrm{L}) n=6 ; 9 ; 5 ; 12 ; 5$ & $4.6 \pm 0.4$ \\
\hline Progesterone $(\mathrm{nmol} / \mathrm{L}) n=6 ; 9 ; 5 ; 12 ; 5$ & $204.7 \pm 11.2$ \\
\hline Estradiol $(\mathrm{pg} / \mathrm{mL}) n=6 ; 9 ; 5 ; 9 ; 5$ & $43.9 \pm 5.8$ \\
\hline Total cholesterol (mmol/L) $n=6 ; 9 ; 5 ; 12 ; 5$ & $1.90 \pm 0.16$ \\
\hline Glucose $(\mathrm{mmol} / \mathrm{L}) n=6 ; 9 ; 5 ; 12 ; 5$ & $6.0 \pm 0.2$ \\
\hline
\end{tabular}

\begin{tabular}{|c|c|}
\hline \multicolumn{2}{|c|}{ Gestation day 21 (G21) } \\
\hline Control & PTU \\
\hline $80.8 \pm 4.8^{a}$ & $37.4 \pm 0.7^{b}$ \\
\hline $6.7 \pm 0.3^{a}$ & $6.3 \pm 0.7$ \\
\hline $362.5 \pm 32.8^{a}$ & $470.9 \pm 64.5$ \\
\hline $69.4 \pm 6.5^{a}$ & $75.9 \pm 12.5$ \\
\hline $3.32 \pm 0.24^{a}$ & $2.39 \pm 0.26^{b}$ \\
\hline $4.1 \pm 0.1^{a}$ & $3.6 \pm 0.3$ \\
\hline
\end{tabular}

\begin{tabular}{|c|c|}
\hline \multicolumn{2}{|c|}{ Postpartum day 14 (P14) } \\
\hline Control & PTU \\
\hline $78.0 \pm 5.3^{a}$ & $39.1 \pm 5.0^{b}$ \\
\hline $4.6 \pm 0.5$ & $4.4 \pm 0.3$ \\
\hline $482.8 \pm 29.6^{a}$ & $505.2 \pm 28.4$ \\
\hline $38.8 \pm 5.4$ & $42.6 \pm 3.5$ \\
\hline $3.31 \pm 0.16^{a}$ & $3.32 \pm 0.29$ \\
\hline $5.5 \pm 0.2$ & $5.0 \pm 0.3$ \\
\hline
\end{tabular}

a $P<0.05$ compared to virgin control.

${ }^{\mathrm{b}} P<0.05$ compared to respective control group (unpaired $t$-test).

\section{Statistical data analysis}

Statistical analysis of data was performed using Student's $t$-test or repeated measures ANOVA accompanied by Bonferroni post-hoc correction, as appropriate. Statistical significance was reached at $P<0.05$. All data are given as mean \pm S.E.M.; $n$ represents the number of animals or the number of samples in qPCR and Western blotting.

\section{Results}

\section{Characteristics of the hypothyroidism model}

The durations of gestation periods were similar in control and PTU-treated dams and averaged 22 days. The hormones levels in virgin control, pregnant (G21) and postpartum (P14) control and PTU rats are shown in Table 2. In blood serum of control rats at G21 and P14, total $\mathrm{T}_{4}$ concentration was reduced compared to virgin control $(P<0.05)$, whereas free $\mathrm{T}_{3}$ concentration was moderately increased on G21 and not changed on P14. PTU treatment resulted in reduced total $\mathrm{T}_{4}$ on both G21 and $\mathrm{P} 14$, but did not affect free $\mathrm{T}_{3}$ concentration. The levels of progesterone in control females, as expected, were higher on G21 and P14 compared to virgin females, while the level of estradiol was elevated only on G21. Neither progesterone nor estradiol concentrations differed between control and PTU-treated females. Total cholesterol concentration in blood serum of control was elevated on G21 and P14 compared to virgin group; PTU treatment resulted in reduced cholesterol on G21 but not on P14 (Table 2). The level of glucose was reduced before delivery (on G21) and restored by P14 with no difference between control and PTU-treated females.

Control and PTU-treated dams did not differ in body weight gain throughout the gestation period (Fig. 1A). The number of pups per litter before culling did not differ

in control and PTU groups $(10.7 \pm 1.1$ in control and $8.3 \pm 1.1$ in PTU, $P>0.05$ ). Average body weight of oneday-old pups did not differ as well $(6.0 \pm 0.2 \mathrm{~g}$ in control and $6.2 \pm 0.1 \mathrm{~g}$ in PTU, $P>0.05$ ). In two weeks, body weights of pups greatly increased but still were similar in the two groups $(29.9 \pm 1.3 \mathrm{~g}$ in control and $27.4 \pm 0.9 \mathrm{~g}$ in PTU, $P>0.05$ ). The total weight of each dam and its progeny during the post-delivery period was comparable in control and PTU groups (Fig. 1A) and the relative water consumption by the groups did not differ as well (Fig. 1B). The average dose of PTU consumed by dams daily was $0.88 \mathrm{mg} / \mathrm{kg}$.

PTU effects on serum levels of thyroid-related hormones in dams whose pups were used in vascular studies (Table 3) were similar to those described above (Table 2). Two weeks after delivery, the dams of PTU group had significantly lower serum levels of total and free $\mathrm{T}_{4}$ than control dams, but the concentration of free $\mathrm{T}_{3}$ was not altered. Along with that, 2-week-old PTU male pups
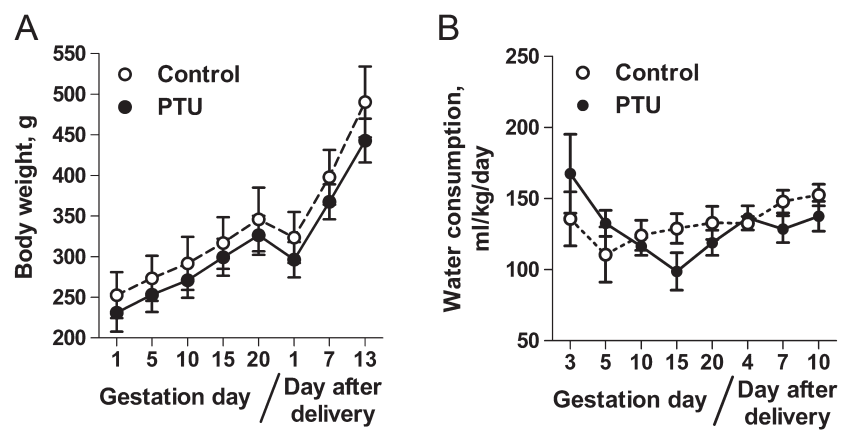

\section{Figure 1}

PTU consumption (7 ppm in drinking water) has no adverse effects on dams. (A) Body weight dynamics of pregnant dams and the dams with their progeny (after delivery) from control $(n=6)$ and PTU $(n=6)$ groups. (B) Average water consumption by dams from control $(n=6)$ and PTU $(n=6)$ groups; the data are normalized to body weight of the dam (during gestation) or to total weight of the dam and litter (after delivery)

๑ 2017 Society for Endocrinology Printed in Great Britain 
Table 3 Blood serum levels of thyroid hormones in dams and their male offspring measured after the end of PTU consumption ( 2 weeks after delivery).

\begin{tabular}{|c|c|c|c|}
\hline & Hormones & Control & PTU \\
\hline \multirow[t]{3}{*}{ Dams $(n=6 ; 6)$} & Total $\mathrm{T}_{4}(\mathrm{nmol} / \mathrm{L})$ & $65.42 \pm 4.85$ & $30.79 \pm 4.95^{a}$ \\
\hline & Free $\mathrm{T}_{4}(\mathrm{pmol} / \mathrm{L})$ & $14.51 \pm 2.83$ & $5.81 \pm 0.40^{a}$ \\
\hline & Free $\mathrm{T}_{3}(\mathrm{pmol} / \mathrm{L})$ & $5.24 \pm 0.70$ & $5.29 \pm 1.56$ \\
\hline \multirow{4}{*}{ Pups $(n=11 ; 19)$} & Total $\mathrm{T}_{4}(\mathrm{nmol} / \mathrm{L})$ & $99.33 \pm 4.59$ & $20.62 \pm 1.72^{a}$ \\
\hline & Free $\mathrm{T}_{4}(\mathrm{pmol} / \mathrm{L})$ & $31.22 \pm 1.54$ & $4.01 \pm 0.13^{a}$ \\
\hline & Total $\mathrm{T}_{3}(\mathrm{nmol} / \mathrm{L})$ & $2.02 \pm 0.11$ & $1.33 \pm 0.10^{a}$ \\
\hline & Free $\mathrm{T}_{3}(\mathrm{pmol} / \mathrm{L})$ & $8.90 \pm 0.86$ & $2.88 \pm 0.36^{a}$ \\
\hline Pups TSH $(n=5 ; 8)$ & $\mathrm{TSH}(\mathrm{ng} / \mathrm{mL})$ & $0.99 \pm 0.06$ & $41.68 \pm 5.27^{a}$ \\
\hline
\end{tabular}

a $P<0.05$ compared to control (unpaired $t$-test).

demonstrated significantly reduced blood concentrations of total and free $\mathrm{T}_{4}$ and $\mathrm{T}_{3}$ in comparison to control group. Remarkably, the contents of total and free $\mathrm{T}_{4}$ decreased drastically, while the levels of $\mathrm{T}_{3}$ were reduced to a lesser extent. In contrast, blood concentration of TSH was greatly increased in 2-week-old PTU pups. In addition, 2-week-old PTU pups demonstrated higher total serum cholesterol concentration compared to control pups $(6.99 \pm 0.41 \mathrm{mmol} / \mathrm{L}(n=14)$ vs $4.82 \pm 0.37 \mathrm{mmol} / \mathrm{L}$ $(n=11), P<0.05)$.

\section{mRNA expression levels of $D 2$ and $T R \alpha_{1}$ in arterial tissue of 2-week-old progeny}

In both control and PTU groups, the level of D2 mRNA in mesenteric arteries was one-third of that in saphenous arteries but did not differ between control and PTU groups in each type of arteries (Fig. 2A). Therefore, two studied arteries may differ prominently in local production of thyroid hormones in control as well as in hypothyroid rats. Of note, D1 and D3 mRNA was not detected in any group of samples, while the efficiency of our qPCR protocol was confirmed by D1 mRNA expression in rat liver and D3 mRNA in rat heart.

$\mathrm{TR} \alpha_{1}$ gene expression did not differ between saphenous and mesenteric arteries (Fig. 2B). It was similar in mesenteric arteries of two studied groups, but was elevated in saphenous artery of PTU rats compared to control.

\section{The parameters of studied arteries}

The relaxed inner diameter $\left(\mathrm{d}_{100}\right)$ of saphenous artery was smaller in PTU group compared to control, while the diameters of mesenteric arteries did not differ in the two groups (Table 4). The isometric contractility (maximum active force) was decreased in both arteries of PTU rats compared to respective controls (Table 4). Vascular smooth muscle differentiation is marked by increased expression of smooth muscle-specific genes, such as SM-MHC, $\alpha$-actin, SERCA2A, SM22 $\alpha$ etc. (Owens et al. 2004). To explore the effect of early thyroid deficiency on vascular smooth muscle maturation, we measured arterial contents of respective mRNAs (Fig. 3). SM-MHC/NM-MHC ratio was significantly lower in mesenteric arteries of control rats in comparison to saphenous artery (Fig. 3A). Antenatal/ early postnatal hypothyroidism reduced relatively high SM-MHC/NM-MHC ratio in saphenous artery, but did not change the ratio in mesenteric arteries (Fig. 3A). The ratio of $\alpha$-actin mRNA to $\beta$-actin mRNA (Fig. 3B) as well as SERCA2A mRNA content (Fig. 3C) did not differ in saphenous and mesenteric arteries of control rats. However, antenatal/early postnatal hypothyroidism was associated with twofold reduction in expression of these marker genes in mesenteric, but not saphenous arteries (Fig. 3B and C). mRNA abundance was significantly higher in saphenous than that in mesenteric arteries of control rats, but was not affected by antenatal/early postnatal hypothyroidism in either artery (Fig. 3D). Finally, the PLB mRNA (Fig. 3E) and LTCC mRNA (Fig. 3F) levels did not differ between two studied arteries and were not affected by antenatal hypothyroidism. Therefore, expression of smooth muscle marker genes demonstrates inter-arterial differences and is differently affected by antenatal/early postnatal hypothyroidism.
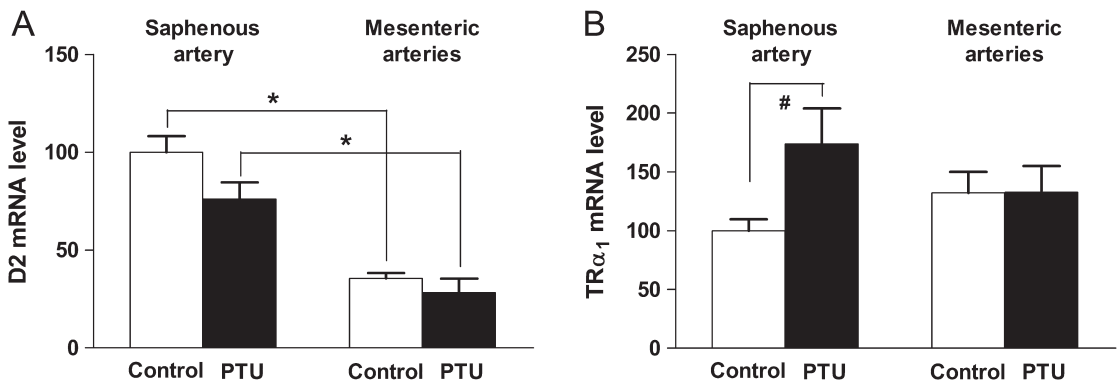

\section{Figure 2}

mRNA expression levels of (A) D2 and (B) TR 1 in saphenous and mesenteric arteries of 2-week-old male rats from control $(n=7 ; 8)$ and PTU $(n=8 ; 5)$ groups. ${ }^{*} P<0.05$ compared to saphenous artery in respective group (unpaired $t$-test). Data are normalized to the geometric mean of the two house-keeping genes (GAPDH and 18S rRNA) in the same tissue sample and shown as the percentage of the mean value for saphenous artery in control group. 
Table 4 Relaxed inner diameter $\left(\mathrm{d}_{100}\right)$ and maximum active force of saphenous and mesenteric arteries in 2-week-old rats from control and PTU groups.

\begin{tabular}{|c|c|c|c|}
\hline Arteries & Parameters & Control & PTU \\
\hline $\begin{array}{l}\text { Saphenous } \\
\qquad(n=7 ; 9)\end{array}$ & $\begin{array}{l}\text { Diameter, } \mu \mathrm{m} \\
\text { Maximum active } \\
\text { force, } \mathrm{mN}\end{array}$ & $\begin{array}{r}274.9 \pm 6.9 \\
11.7 \pm 0.7\end{array}$ & $\begin{array}{c}240.3 \pm 12.4^{a} \\
8.7 \pm 0.6^{a}\end{array}$ \\
\hline $\begin{array}{c}\text { Mesenteric } \\
(n=10 ; 9)\end{array}$ & $\begin{array}{l}\text { Diameter, } \mu \mathrm{m} \\
\text { Maximum active } \\
\text { force, } \mathrm{mN}\end{array}$ & $\begin{array}{r}184.6 \pm 4.6 \\
4.4 \pm 0.3\end{array}$ & $\begin{array}{r}181.4 \pm 3.5 \\
3.3 \pm 0.2^{\mathrm{a}}\end{array}$ \\
\hline
\end{tabular}

a $P<0.05$ compared to control (unpaired $t$-test).

The effects of hypothyroidism on the NO pathway activity in arteries of 2-week-old rats

The activity of endothelial NO pathway was assessed by the procontractile action of NOS inhibitor L-NNA in comparison to its inactive analogue D-NNA (Gaynullina et al. 2013). The responses of saphenous arteries to MX in the presence of D-NNA were similar in control and PTU rats (Fig. 4A). L-NNA caused a moderate tonic contraction of arterial preparations, which corresponds to baseline force elevation by about $5 \%$ of maximum (Fig. 4B). L-NNA also augmented arterial sensitivity to $\mathrm{MX}: \mathrm{pD}_{2}$ values in control group were $4.98 \pm 0.09$ and $5.57 \pm 0.24$ for D-NNA and L-NNA, respectively $(P<0.05) ; \mathrm{pD}_{2}$ values in PTU group were $4.81 \pm 0.24$ and $5.44 \pm 0.15$ for D-NNA and L-NNA, respectively $(P<0.05)$. However, the responses to MX in the presence of L-NNA did not differ in two groups (Fig. 4B). The relaxatory responses to exogenous NO donor DEA/NO of endotheliumdenuded saphenous arteries were also similar in control and PTU groups (Fig. 4C). No difference in eNOS protein content in saphenous arteries was observed as well (Fig. 4D).

The contractile responses of mesenteric arteries to MX in the presence of D-NNA were similar in two studied groups (Fig. 5A). However, the responses of mesenteric arteries in the presence of L-NNA were evidently different in control and PTU rats (Fig. 5B). Incubation with L-NNA led to tonic contraction of control arteries up to $50 \%$ of maximum and shifted their MX concentration-
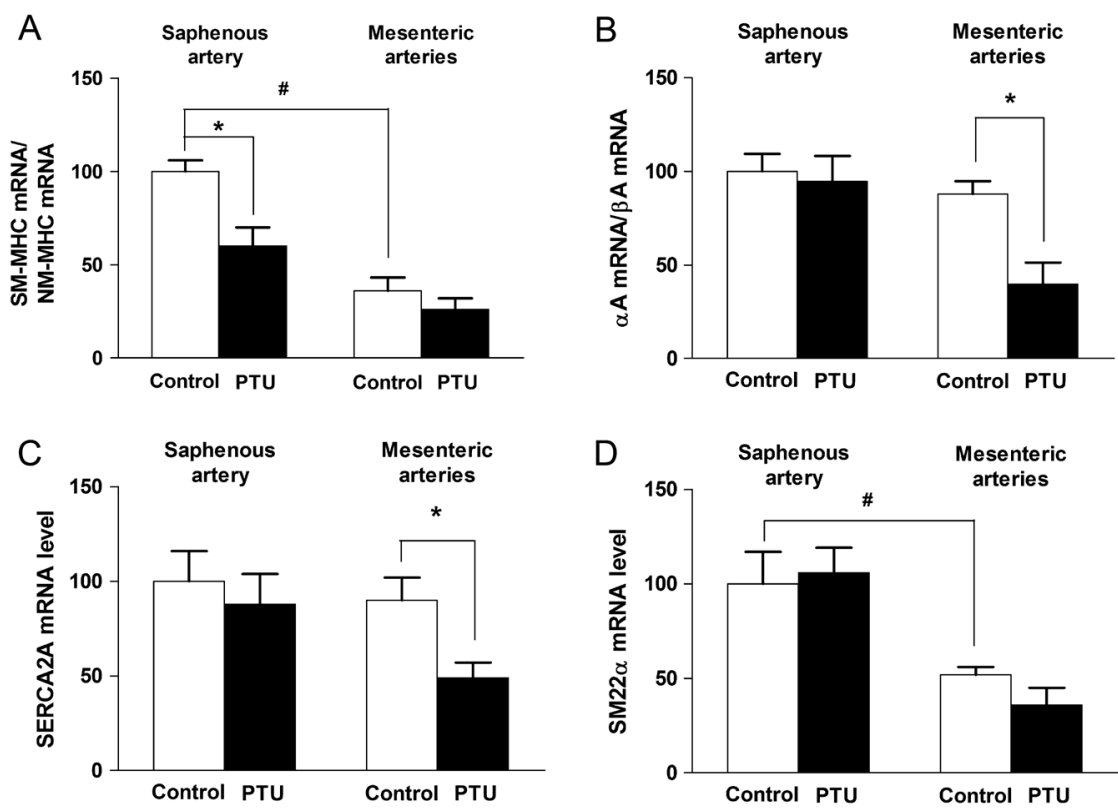

Figure 3

mRNA contents of smooth muscle differentiation markers in saphenous and mesenteric arteries of 2-week-old control $(n=7 ; 8)$ and PTU $(n=8 ; 5)$ male rats. (A) SM-MHC/NM-MHC mRNAs ratio;
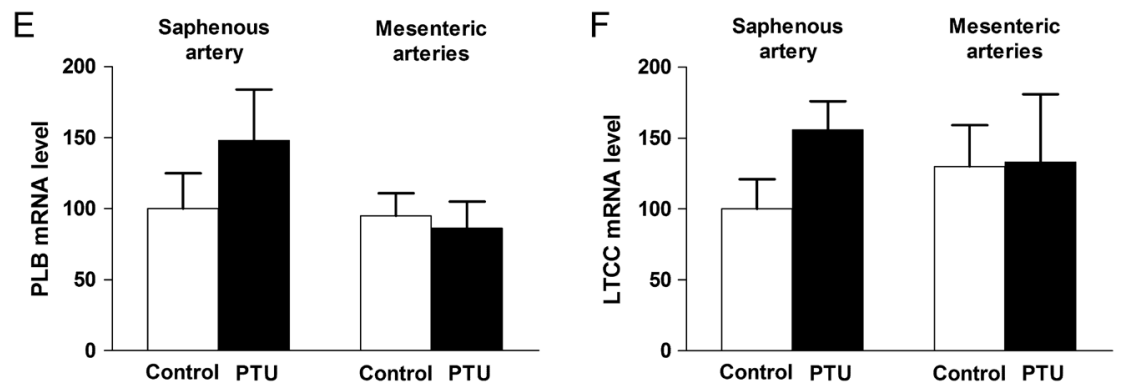

(B) $\alpha$-actin $(\alpha A) / \beta$-actin $(\beta A)$ mRNAs ratio;

(C) SERCA2A mRNA; (D) SM2 $\alpha$ mRNA;

(E) phospholamban and (F) L-type $\mathrm{Ca} 2+$ channel. $\star P<0.05$ compared to control; $\# P<0.05$ compared to saphenous artery in respective group (unpaired $t$-test). In (C), (D), (E) and (F) data are normalized to the geometric mean of the two house-keeping genes (GAPDH and 18S rRNA) in the same tissue sample. Data are shown as the percentage of the mean value for saphenous artery in control group. 
A

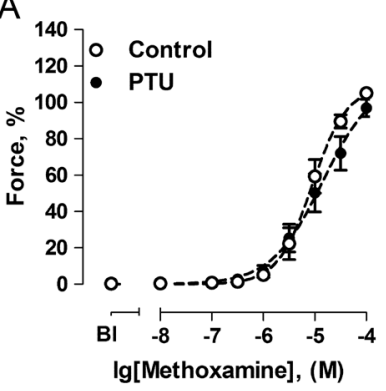

B

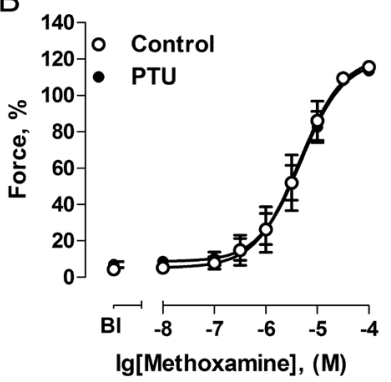

C

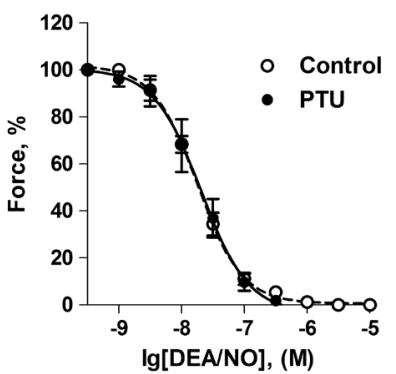

$\mathrm{D}$

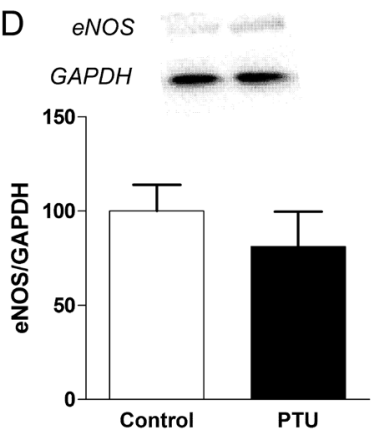

Figure 4

Antenatal hypothyroidism does not change the NO-mediated anticontractile effect in saphenous arteries of 2-week-old rats. Panels A and $\mathrm{B}$ : Contractile responses to $\mathrm{MX}$ of endothelium-intact saphenous arteries from control $(n=7)$ and PTU $(n=12)$ rats in the presence of $100 \mu \mathrm{mol} / \mathrm{L}$ D-NNA (A) or $100 \mu \mathrm{mol} / \mathrm{L}$ L-NNA (B). BI - baseline active force value before the first $M X$ concentration. Panel $C$ : Dilatory response to DEA/NO of endothelium-denuded saphenous arteries from control $(n=5)$ and PTU $(n=4)$ rats. Panel D: Relative content of eNOS protein in saphenous arteries of control $(n=5)$ and PTU $(n=6)$ rats. In A and B, the data are given as the percentage of maximum active force (see Table 4). In $\mathrm{C}$, the responses are expressed as the percentage of the precontraction level. In D the data are normalized to GAPDH in the same tissue sample, average ratio in control group is presented as $100 \%$.

response curves to the left $\left(\mathrm{pD}_{2}\right.$ values were $5.41 \pm 0.09$ and $6.68 \pm 0.31$ for D-NNA and L-NNA, respectively, $P<0.05$ ) (Fig. 5A and B). Generally, L-NNA effects on mesenteric arteries were more prominent than those in saphenous arteries (Fig. 4A and B and Fig. 5A and B). In arteries of PTU rats, L-NNA also induced basal tone and increased MX-induced contractile responses $\left(\mathrm{pD}_{2}\right.$ values were $5.23 \pm 0.12$ and $5.96 \pm 0.24$ for D-NNA and L-NNA, respectively, $P<0.05)$. However, as seen in Fig. 5B, L-NNA curve for PTU rats was shifted down and to the right compared to the L-NNA curve for control group. Notably, such reduced effect of NOS inhibitor in the mesenteric arteries of PTU rats was not due to the decreased smooth muscle sensitivity to NO. Just the opposite, the responsiveness of endothelium-denuded mesenteric arteries to DEA/NO was augmented in PTU compared to control rats (Fig. 5C). No difference in eNOS protein content was observed between two groups

A

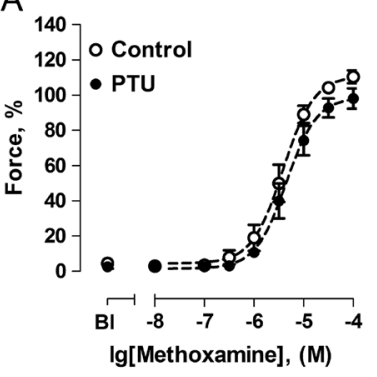

B

C

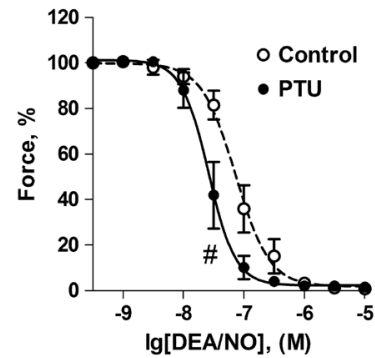

$\mathrm{E}$

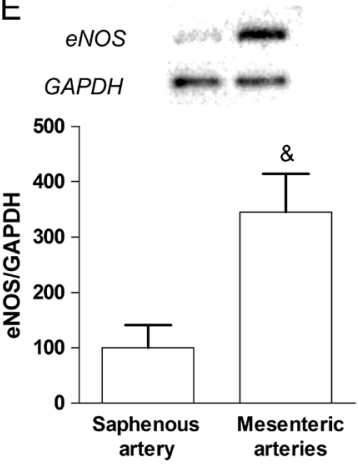

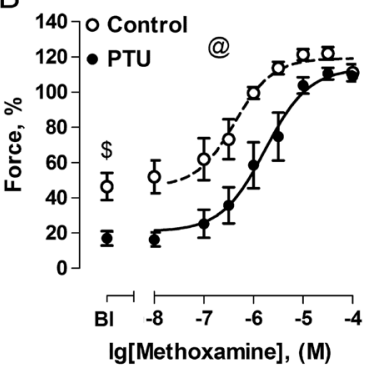

D eNOS mant.

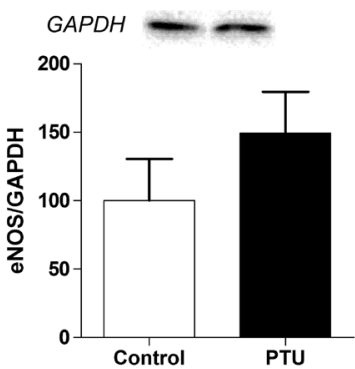

$\mathrm{F}$

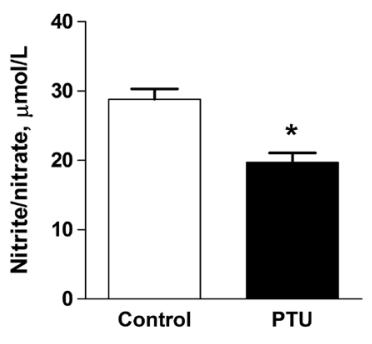

Figure 5

Antenatal hypothyroidism reduces the anticontractile effect of NO in small mesenteric arteries of 2-week-old rats. Panels A and B: Contractile responses to $\mathrm{MX}$ of endothelium-intact mesenteric arteries from control $(n=7)$ and PTU $(n=9)$ rats in the presence of $100 \mu \mathrm{mol} / \mathrm{L}$ D-NNA $(\mathrm{A})$ or $100 \mu \mathrm{mol} / \mathrm{L}$ L-NNA (B). BI - baseline active force value before the first $\mathrm{MX}$ concentration. Panel C: Dilatory response to DEA/NO of endotheliumdenuded mesenteric arteries from control $(n=10)$ and PTU $(n=4)$ rats. Panel D: Relative content of eNOS protein in mesenteric arteries of control $(n=5)$ and PTU $(n=6)$ rats. Panel E: eNOS protein content in saphenous $(n=6)$ and mesenteric $(n=6)$ arteries of 2-week-old control rats. Panel F: The levels of NO metabolites (nitrites and nitrates) in blood serum of control $(n=20)$ and PTU $(n=22)$ rats. In A and B the data are given as the percentage of maximum active force (see Table 4). $\$ P<0.05$ - comparison of basal active force values for Control and PTU groups (unpaired $t$-test); ${ }^{\circledR} P<0.05$ - comparison between Control and PTU curves in the presence of L-NNA in the range of MX concentrations from $10-8 \mathrm{~mol} / \mathrm{L}$ to $10-4 \mathrm{~mol} / \mathrm{L}$ (Repeated measures ANOVA with Bonferroni post-hoc test). In $C$ the responses are expressed as the percentage of the precontraction level: ${ }^{P}<0.05$ compared to Control (Repeated measures ANOVA with Bonferroni post-hoc test). In D and $\mathrm{E}$ the data are normalized to GAPDH in the same tissue sample, in D average ratio in control group is presented as $100 \%$, in $\mathrm{E}$ average ratio in saphenous artery is presented as $100 \%$. \& $P<0.05$ - compared to saphenous artery (unpaired $t$-test); ${ }^{*} P<0.05$ - compared to control (unpaired $t$-test). 


\section{Figure 6}

Antenatal hypothyroidism has no impact on Rho-kinase pathway in saphenous arteries of 2-week-old rats. Panels A and B: Contractile

A

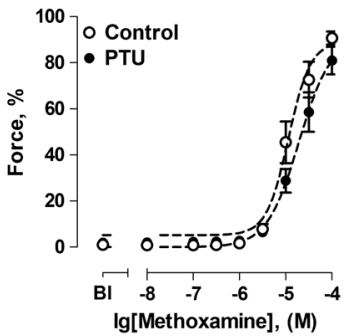

B

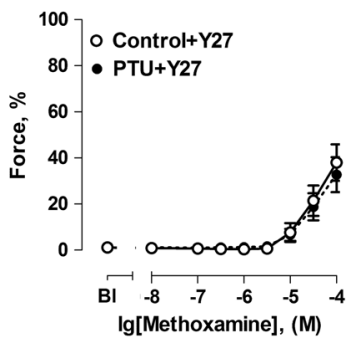

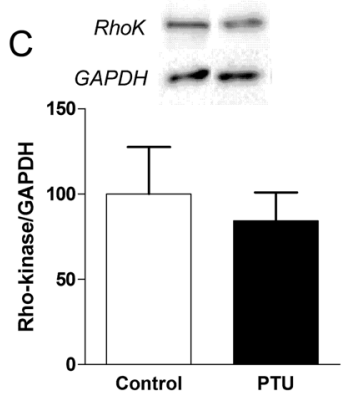
responses to $M X$ of endothelium-intact saphenous arteries from control and PTU rats in the presence of vehicle (A, $n=7$ for control and $n=8$ for PTU) or $3 \mu \mathrm{mol} / \mathrm{L}$ Rho-kinase inhibitor Y27632 (B, $n=7$ for control and $n=9$ for PTU). Panel C: Relative content of Rho-kinase protein in saphenous arteries of control $(n=6)$ and PTU $(n=6)$ rats. In A and B the data are given as the percentage of maximum active force (see Table 4). In C the data are normalized to GAPDH in the same tissue sample, average ratio in control group is presented as $100 \%$.
(Fig. 5D). Importantly, iNOS mRNA was not detected in any of the studied samples, while it was easily detected in tissue samples from rat heart with ischemia-reperfusion injury, indicating the adequacy of our qPCR analysis.

Regarding diverse effects of hypothyroidism on NO pathway in two studied arteries we compared the contents of eNOS protein in the arteries of control 2-week-old rats. As shown in Fig. 5E, mesenteric arteries had several-fold higher eNOS protein content than saphenous arteries. Therefore, hypothyroidism weakened the anticontractile influence of $\mathrm{NO}$ in arteries with higher eNOS content (mesenteric) but did not alter it in arteries with lower eNOS content (saphenous).

To compare the systemic NO production in 2-weekold control and PTU rats, we measured concentrations of NO metabolites in their blood serum. The total content of nitrate and nitrite was significantly lower in PTU rats (Fig. 5F).

\section{The effects of hypothyroidism on the Rho-kinase role in arterial contraction in 2 -week-old rats}

To identify the role of Rho-kinase in the regulation of contractile responses to $\mathrm{MX}$ in saphenous arteries of control and PTU rats we used Rho-kinase inhibitor Y27632. Saphenous arteries of control and PTU rats showed similar responses to $\mathrm{MX}$ in the presence of vehicle (Fig. 6A). Y27632 markedly reduced the responses to MX in both groups (Fig. 6B). Since pD2 values cannot be estimated for non-saturated Y27632 curves, as an alternative we calculated the active force at the highest concentration of MX $(100 \mu \mathrm{mol} / \mathrm{L})$ as a percentage of the maximal active force in the first concentrationresponse relationship. Force values in control group were $91 \pm 3 \%$ and $38 \pm 8 \%$ in the presence of vehicle and Y27632, respectively $(P<0.05)$; force values in
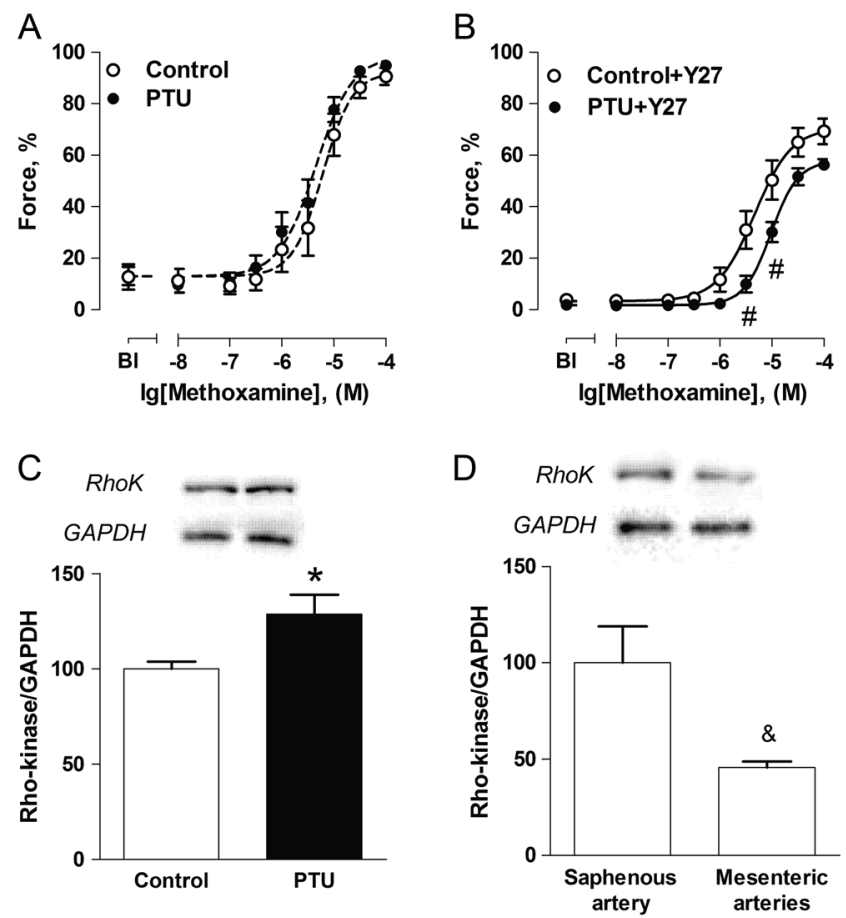

Figure 7

Antenatal hypothyroidism increases Rho-kinase procontractile effect and expression in mesenteric arteries of 2-week-old rats. Panels A and B: Contractile responses to $\mathrm{MX}$ of endothelium-intact mesenteric arteries from control $(n=10)$ and PTU $(n=9)$ rats in the presence of vehicle (A) or $3 \mu \mathrm{mol} / \mathrm{L}$ Rho-kinase inhibitor Y27632 (B). Panel C: Relative content of Rho-kinase protein in mesenteric arteries of control $(n=6)$ and PTU $(n=6)$ rats. Panel D: Rho-kinase protein content in saphenous $(n=6)$ and mesenteric $(n=6)$ arteries of 2-week-old control rats. In A and B, the data are given as the percentage of maximum active force (see Table 4). ${ }^{\#} P<0.05$ - comparison between Control and PTU curves in the presence of Y27632 (Repeated measures ANOVA with Bonferroni post-hoc test). In C and D the data are normalized to GAPDH in the same tissue sample, in $C$ average ratio in control group is presented as $100 \%$, in $D$ average ratio in saphenous artery is presented as $100 \%$. ${ }^{*} P<0.05$ - compared to control (unpaired $t$-test); \& $P<0.05$ compared to saphenous artery (unpaired $t$-test)
๑ 2017 Society for Endocrinology Printed in Great Britain 
PTU group were $81 \pm 6 \%$ and $33 \pm 8 \%$ in the presence of vehicle and Y27632, respectively $(P<0.05)$. No difference was observed between control and PTU groups in the presence of Y27632 (Fig. 6B). Thus, hypothyroidism did not change the role of Rho-kinase in contractile responses of saphenous artery. This is consistent with unchanged protein content of Rho-kinase in saphenous artery of PTU compared to control rats (Fig. 6C).

In the same manner, the role of Rho-kinase in the regulation of mesenteric arteries contractile responses was studied in 2-week-old control and PTU rats. In the absence of Y27632, the responses of these arteries to MX were similar in control and PTU rats (Fig. 7A). Incubation of mesenteric arteries with Y27632 significantly reduced the contractile response to $\mathrm{MX}$ in both groups (Fig. 7A and B). Force values at $100 \mu \mathrm{mol} / \mathrm{L} \mathrm{MX}$ in control group were $91 \pm 3 \%$ in the presence of vehicle and $69 \pm 5 \%$ in the presence of Y27632 $(P<0.05)$; respective force values in PTU group were $95 \pm 2 \%$ and $56 \pm 2 \%(P<0.05)$. However, in the presence of Y27632 moderate MX concentrations induced weaker contractile responses in PTU group when compared to control group (Fig. 7B). This indicates increased contribution of Rho-kinase to the regulation of arterial contraction in response to $\alpha_{1}$-adrenoceptor agonist in the PTU group. Along with that Rho-kinase, protein content was elevated in mesenteric arteries of PTU rats compared to control rats (Fig. 7C).

Notably, in control pups, the inhibitory effect of Y27632 on saphenous arteries (Fig. 6A and B) was higher compared to mesenteric arteries (Fig. 7A and B). This observation goes in accordance with higher content of Rhokinase protein in saphenous arteries than in mesenteric (Fig. 7D). Therefore, hypothyroidism strengthened the functional role of Rho-kinase in arteries with lower Rhokinase content (mesenteric) but did not alter it in arteries with higher Rho-kinase content (saphenous).

\section{Discussion}

Here, we studied the vascular alterations in rats with antenatal/early postnatal hypothyroidism, which were not associated with change in pregnancy duration in dams and growth retardation in their progeny. Two-weekold male offspring of PTU-treated dams, as compared to controls, demonstrated decreased contractility and delayed maturation of arterial smooth muscle. For the first time, we showed that early hypothyroidism can alter arterial contractility in 2-week-old pups via two mechanisms: by decreasing the anticontractile effect of NO pathway and by increasing the contribution of procontractile Rho-kinase pathway. The diversity of early hypothyroidism effects in two studied arteries was associated with the differences in expression levels of D2 and genes-markers of smooth muscle differentiation as well as in the intrinsic activity of signaling pathways targeted by thyroid hormones.

\section{PTU effects in dams and their male offspring}

In rats, the thyroid gland organogenesis occurs later than in humans, so that it continues during several weeks of postnatal development (Forhead \& Fowden 2014). As in several preceding studies, our dams were treated with PTU during the whole period of pregnancy and also after delivery. PTU dose was suggested to be moderate, but enough to suppress the synthesis of thyroid hormones (Taylor et al. 2008, Shibutani et al. 2009, Chakraborty et al. 2012). Higher doses of PTU can exert negative effects on the course of pregnancy, lactation and progeny survival (Hapon et al. 2003, 2007, Silva et al. 2012, Mallela et al. 2014). In our study, PTU (7 ppm) did not affect the duration of gestation, litter size and body weight of pups, which is supported by the results of previous studies using PTU in similar dose range (Taylor et al. 2008, Shibutani et al. 2009, Chakraborty et al. 2012). PTU also had no effect on free $T_{3}$, progesterone, estradiol and glucose blood contents during pregnancy and after delivery. Further, our PTU-treated females did not demonstrate an increase in total blood cholesterol, unlike females treated with higher PTU doses (Hapon et al. 2005). Of note, consumption of PTU in doses about several $\mathrm{mg}$ per $\mathrm{kg}$ did not increase serum cholesterol in adult rats (Suzuki \& O'Neal 1967). In contrast, PTU treatment resulted in reduced cholesterol level on G21, which may be associated with cholesterol transport across the placenta to the fetus. Altogether, we consider that our dams suffered from a mild hypothyroidism.

Along with that, the progeny of PTU-treated dams experienced more prominent lack of thyroid hormones. Transfer of PTU to pups body may occur through placenta (Mortimer et al. 1997) and, after birth, with dam's milk. Stronger influence of PTU on thyroid hormones levels in pups may be due to higher susceptibility of developing thyroid gland to PTU. Well-known consequence of thyroid hormones lowering is an increase of TSH blood concentration (Shibutani et al. 2009, Chakraborty et al. 2012). In our study, TSH level was much higher in

Published by Bioscientifica Ltd 
PTU 2-week-old rats, which again indicates the strong disruption of thyroid secretion.

\section{Transcripts of D2 and TR $\alpha_{1}$ genes are observed in small arteries of 2-week-old rats}

D2 enzyme converts $T_{4}$ into more potent $T_{3}$ and $T R \alpha_{1}$ is a predominant receptor that mediates $\mathrm{T}_{4}$ and $\mathrm{T}_{3}$ effects in endothelial and smooth muscle cells (Yasuzawa-Amano et al. 2004, Hiroi et al. 2006, Gereben et al. 2008, Makino et al. 2012). We are the first to show that D2 mRNA expression can vary significantly between small arteries of 2-week-old rats. According to our data, D2 mRNA level in mesenteric arteries is several times lower than that in saphenous artery. The D2 mRNA level was shown to correlate with the D2 enzyme activity in brain, skeletal muscle and brown adipose tissue of rats (Nagao et al. 2014). Assuming such correlation in vascular tissue, we would expect lower D2 activity as a reason for particular susceptibility of the mesenteric arteries to the thyroid hormones deficiency.

While the tissue-specific D2 expression is evident, its mechanisms remain poorly understood (Dentice et al. 2013). We suppose that elevated D2 expression level in saphenous artery may be associated with its thermoregulatory function. Since thyroid hormones are major stimulators of thermogenesis (Mullur et al. 2014), cutaneous arteries that control heat dissipation from the skin may require more intensive local $\mathrm{T}_{3}$ production than arteries of other organs, including intestine. Indeed, a disruption of thyroid hormone signaling more prominently impairs tone regulation of thermoregulatory tail artery compared to mesenteric arteries in mice (Warner et al. 2013).

D2 gene expression in arteries was not changed by antenatal/early postnatal hypothyroidism, in contrast to the previous findings on increased content and activity of D2 in hypothalamus of hypothyroid pups (Taylor et al. 2008, Sharlin et al. 2010). Probably, the regulation of D2 expression during hypothyroidism is tissue specific and the lack of D2 increase in vasculature may reflect a particular vulnerability of blood vessels to the endocrine disruption.

The level of TR $\alpha_{1}$ mRNA was higher in saphenous artery of hypothyroid rats, but was not altered in mesenteric arteries. Similarly, diverse effects of hypothyroidism on TR $\alpha$ were shown previously in two periureteral muscles of rabbits (Sánchez-García et al. 2015). This indicates that the level of thyroid hormones can exert non-uniform effects on expression of their receptors in different tissues.

\section{The influence of antenatal/early postnatal hypothyroidism on arterial characteristics}

Our findings indicate that antenatal/early postnatal hypothyroidism diminished maximum contractile force of saphenous and small mesenteric arteries, which suggests reduced media thickness in their walls (Mulvany \& Halpern 1977). Along with that, in the developing arteries, the maturity of the contractile apparatus may affect the contractility considerably. Indeed, reduced level of SM-MHC in relation to NM-MHC was observed in saphenous arteries of 2-week-old offspring of PTU dams, which is typical for immature smooth muscle in comparison to adult (Eddinger \& Murphy 1991, Reho et al. 2014). This goes in accordance with the diminished maximum contractile force of saphenous artery. Further, $\alpha$-actin-to- $\beta$-actin ratio was significantly attenuated in mesenteric arteries of PTU rats pointing to their immature state (Eddinger \& Murphy 1991, Reho et al. 2014). Similar to $\alpha / \beta$-actin ratio, SERCA2A gene expression, which also marks the differentiation of smooth muscle cells (Vallot et al. 2000), was suppressed in mesenteric arteries by the antental/early postnatal hypothyroidism.

Therefore, thyroid hormones deficiency might retard the development of arterial smooth muscle. Such suggestion goes in accordance with previous observation that thyroid hormones drive the maturation of cardiomyocytes (Chattergoon et al. 2012) and increase the expression of $\alpha$-actin in coronary arterioles (Savinova et al. 2011). Moreover, our data on SERCA2A expression profile suggests that intracellular $\mathrm{Ca}^{2+}$-homeostasis in smooth muscle cells of mesenteric arteries may be affected by antenatal/early postnatal hypothyroidism. However, based on the fact that LTCC and PLB expression levels did not differ between saphenous and mesenteric arteries and were not affected by hypothyroidism, we can conclude that observed differences in contractile responses are most probably due to alterations in $\mathrm{Ca}^{2+}$ sensitivity than in $\mathrm{Ca}^{2+}$ homeostasis.

\section{The influence of antenatal/early postnatal hypothyroidism on NO pathway}

Developing vasculature of early postnatal rats is protected from high blood pressure by NO, which is tonically produced by the endothelium (Gaynullina et al. 2013,

Published by Bioscientifica Ltd 
Sofronova et al. 2016). Of note, thyroid hormones are established regulators of endothelial NO pathway activity (McAllister et al. 2005, Vargas et al. 2006, Carmona et al. 2014, Jeddi et al. 2015, Obradovic et al. 2016). Here, we demonstrate a novel finding that antenatal/early postnatal hypothyroidism alters NO-dependent control of mesenteric arteries in 2-week-old rats, as was seen from less prominent procontractile effect of NOS inhibitor. Such suppression of NO-pathway was not associated with decreased content of eNOS protein, but with elevated NO-responsiveness of smooth muscle. As smooth muscle sensitivity to exogenous $\mathrm{NO}$ is inversely related to the rate of NO synthesis in vascular endothelium (Ohashi et al. 1998, Brandes et al. 2000), our observations speak in favor of decreased NO availability in mesenteric arteries of 2-week-old hypothyroid pups. Along with that, the antenatal/early postnatal hypothyroidism also caused a significant decrease of NO metabolites level in blood of 2-week-old rats, which is supported by previous studies (Jeddi et al. 2015). Therefore, the lack of thyroid hormones in young organism suppresses the NO production in many vascular beds, which, in turn, can provoke hypertensive episodes and, therefore, increase the risk of immature heart and/or vasculature injury.

\section{The influence of antenatal/early postnatal hypothyroidism on Rho-kinase pathway}

Rho-kinase is a key determinant of $\mathrm{Ca}^{2+}$ sensitivity of arterial smooth muscle contraction and its expression level and functional role are augmented in early postnatal period (Akopov et al. 1998, Mochalov et al. 2008, Puzdrova et al. 2014). In the present study, we showed for the first time that antenatal/early postnatal hypothyroidism may stimulate the expression of Rho-kinase and activity of this signaling pathway in mesenteric arteries of 2-week-old animals. We suggest several mechanisms responsible for stimulation of Rho-kinase pathway under thyroid deficiency.

Firstly, it may take place through the effect on smooth muscle cells differentiation. Proliferating vascular smooth muscle cells were shown to exhibit enhanced contribution of Rho-kinase to the contractile responses (Nishimura et al. 2006). Our data on smaller $\alpha$-actin/ $\beta$-actin ratio and SERCA2A mRNA content in mesenteric arteries of PTU group indicate relative immaturity of their smooth muscle, which may be due to the weakness of maturational effects of thyroid hormones (Savinova et al. 2011, Chattergoon et al. 2012). Moreover, TSH, which is elevated in PTU rats, could stimulate the phenotypic change of vascular smooth muscle cells from the mature contractile phenotype to the young synthetic phenotype (Tian et al. 2014). Taking together, these data point to the assumption that elevated Rho-kinase-dependent contraction in arteries of PTU pups is driven by hypothyroid status per se.

The second mechanism concerns the effect of thyroid deficiency on cholesterol metabolism. Cholesterol is known to prime Rho-kinase pathway in vascular smooth muscle (Morikage et al. 2006). Total cholesterol blood level was shown to be elevated by thyroid deficiency in adults (Duntas \& Brenta 2012) and newborns (Akin et al. 2013). Our 2-week-old PTU rats also demonstrated high serum cholesterol level, which might stimulate the activity/expression of Rho-kinase in smooth muscle cells of their arteries.

In addition, developmental hypothyroidism was shown to decrease the expression level of microtubuleassociated protein TAU (Wei et al. 2013), which recently was shown to be functionally important in cardiovascular system. TAU deficiency results in increased arterial contractility (Betrie et al. 2017). Remarkably, microtubule destabilization has been shown to increase the contractility of vascular smooth muscle via activation of Rho-kinase signaling pathway (Chitaley \& Webb 2002, Platts et al. 2002). Therefore, TAU-dependent processes might stimulate Rho-kinase activity in arteries of rats with antenatal/early postnatal hypothyroidism.

Remarkably, Rho-kinase was shown to be involved in the pathogenesis of a wide range of cardiovascular diseases such as arterial hypertension, coronary vasospasm, aortic aneurism etc. (Shimokawa et al. 2016). Overactivity of this signaling pathway in newborns with hypothyroidism may be the reason for increased risk of early vascular pathologies such as atherosclerosis (Akin et al. 2013).

\section{Diverse effects of antenatal/early postnatal hypothyroidism in different vascular beds}

We observed the effects of early hypothyroidism on activities of $\mathrm{NO}$ and Rho-kinase pathways in mesenteric arteries, but not in saphenous artery. Such diverse action of thyroid deficiency may be due to several reasons. As D2 expression level is several-fold higher in saphenous compared to mesenteric arteries, saphenous arteries could possess a higher rate of local $\mathrm{T}_{3}$ synthesis and, therefore, be less challenged by hypothyroidism. On the other hand, the shortage of $T_{3}$ effects may delay maturation of mesenteric arteries in postnatal period. This suggestion is supported by our data on reduced SM22 $\alpha$ expression

Published by Bioscientifica Ltd 
and SM-MHC/NM-MHC ratio in mesenteric arteries as compared to saphenous ones.

One more reason for diverse effects of hypothyroidism on two studied arteries could be different importance of these two pathways in mesenteric and saphenous arteries of euthyroid pups. Notably, eNOS protein content and the effect of L-NNA were much lower in saphenous arteries compared to mesenteric. This indicates relatively weak regulatory role of NO-pathway in saphenous arteries, which may limit the suppressive effect of thyroid hormones deficiency on eNOS pathway. By contrast, Rhokinase abundance and the effect of its inhibitor were much lower in mesenteric arteries compared to saphenous. Therefore, the stimulation of Rho-kinase pathway under hypothyroidism is more expected in mesenteric artery than in saphenous, where Rho-kinase level and activity are already high.

In conclusion, the present study explores the influence of antenatal/early postnatal hypothyroidism on the activity of two vasomotor mechanisms that are important for young vasculature. Circulatory system of young developing organism possesses strong anticontractile effect of $\mathrm{NO}$ and high activity of Rho-kinase pathway. In mesenteric arteries of young rats, antenatal/early postnatal hypothyroidism diminishes anticontractile action of $\mathrm{NO}$ and stimulates procontractile Rho-kinase pathway. Remarkably, these signaling pathways share their targets at the level of smooth muscle contractile apparatus (Somlyo \& Somlyo 2003). Both pathways regulate the activity of myosin light chain phosphatase (MLCP) via phosphorylation of its regulatory subunit (MYPT1) at different sites. The effects of such phosphorylation are opposite: while activation of NO pathway results in the increase of MLCP activity, Rho-kinase inhibits MLCP. Thus, antenatal/ early postnatal hypothyroidism can increase the level of myosin light chain phosphorylation and smooth muscle contraction via simultaneous depression of NO pathway and augmentation of Rho-kinase pathway in arteries of young rats. This, in turn, potentiates procontractile mechanisms of vasomotor responses in young hypothyroid animals, which may disturb cardiovascular homeostasis during perinatal challenges and have consequences in adulthood.

\section{Declaration of interest}

The authors declare that there is no conflict of interest that could be perceived as prejudicing the impartiality of the research reported.

\section{Funding}

This study was supported by the Russian Science Foundation (grant N1415-00704).

\section{Acknowledgments}

The authors thank Dr Maria Davydova for providing CDNA from rat heart with ischemia-reperfusion injury and Prof. Alexey Katrukha for supplying GAPDH antibody.

\section{References}

Akin MA, Sarici D, Yikilmaz A, Akin L, Gunes T, Ozturk MA \& Kurtoglu S 2013 Aortic intima-media thickness in newborns with congenital hypothyroidism. Hormone Research in Pediatrics 80 267-272. (doi:10.1159/000354688)

Akopov SE, Zhang L \& Pearce WJ 1998 Regulation of Ca2+ sensitization by PKC and rho proteins in ovine cerebral arteries: effects of artery size and age. American Journal of Physiology 275 H930-H939.

Betrie AH, Ayton S, Bush AI, Angus JA, Lei P \& Wright CE 2017 Evidence of a cardiovascular function for microtubule-associated protein tau. Journal of Alzheimer's Disease 56 849-860. (doi:10.3233/JAD-161093)

Bower BD 1957 Peripheral vasomotor function in cretinism. Archives of Disease in Childhood 32 318-324. (doi:10.1136/adc.32.164.318)

Brandes RP, Kim D, Schmitz-Winnenthal FH, Amidi M, Gödecke A, Mülsch A \& Busse R 2000 Increased nitrovasodilator sensitivity in endothelial nitric oxide synthase knockout mice: role of soluble guanylyl cyclase. Hypertension 35 231-236. (doi:10.1161/01. HYP.35.1.231)

Breall JA, Rudolph AM \& Heymann MA 1984 Role of thyroid hormone in postnatal circulatory and metabolic adjustments. Journal of Clinical Investigation 73 1418-1424. (doi:10.1172/JCI111346)

Carmona Y V, Coria MJ, Oliveros LB \& Gimenez MS 2014 Hypothyroidism and oxidative stress: differential effect on the heart of virgin and pregnant rats. Hormone and Metabolic Research 46 14-20. (doi:10.1055/s-0033-1349883)

Chakraborty G, Magagna-Poveda A, Parratt C, Umans JG, MacLusky NJ \& Scharfman HE 2012 Reduced hippocampal brain-derived neurotrophic factor (BDNF) in neonatal rats after prenatal exposure to propylthiouracil (PTU). Endocrinology 153 1311-1316. (doi:10.1210/en.2011-1437)

Chattergoon NN, Giraud GD, Louey S, Stork P, Fowden AL \& Thornburg KL 2012 Thyroid hormone drives fetal cardiomyocyte maturation. FASEB Journal 26 397-408. (doi:10.1096/fj.10-179895)

Chitaley K \& Webb RC 2002 Microtubule depolymerization facilitates contraction of rat aorta via activation of Rho-kinase. Vascular Pharmacology 38 157-161. (doi:10.1016/S1537-1891(02)00163-5)

Davis PJ, Sudha T, Lin H-Y \& Mousa SA 2015 Thyroid hormone, hormone analogs, and angiogenesis. In Comprehensive Physiology, pp 353-362. Hoboken, NJ, USA: John Wiley \& Sons, Inc. (doi:10.1002/cphy. c150011)

Dentice M, Marsili A, Zavacki A, Larsen PR \& Salvatore D 2013 The deiodinases and the control of intracellular thyroid hormone signaling during cellular differentiation. Biochimica et Biophysica Acta 1830 3937-3945. (doi:10.1016/j.bbagen.2012.05.007)

Duntas LH \& Brenta G 2012 The effect of thyroid disorders on lipid levels and metabolism. Medical Clinics of North America 96 269-281. (doi:10.1016/j.mcna.2012.01.012)

Eddinger TJ \& Murphy RA 1991 Developmental changes in actin and myosin heavy chain isoform expression in smooth muscle. Archives of Biochemistry and Biophysics 284 232-237. (doi:10.1016/00039861(91)90290-Y) http://joe.endocrinology-journals.org

DOI: $10.1530 / \mathrm{JOE}-17-0225$ (c) 2017 Society for Endocrinology Printed in Great Britain 
Forhead AJ \& Fowden AL 2014 Thyroid hormones in fetal growth and prepartum maturation. Journal of Endocrinology 221 R87-R103. (doi:10.1530/JOE-14-0025)

Gaynullina D, Lubomirov LT, Sofronova SI, Kalenchuk VU, Gloe T, Pfitzer G, Tarasova OS \& Schubert R 2013 Functional remodelling of arterial endothelium during early postnatal development in rats. Cardiovascular Research 99 612-621. (doi:10.1093/cvr/cvt138)

Gaynullina D, Sofronova S, Selivanova E, Shvetsova A, Borzykh A, Sharova A, Kostyunina D, Martyanov A \& Tarasova O 2017 NO-mediated anticontractile effect of the endothelium is abolished in coronary arteries of adult rats with antenatal/early postnatal hypothyroidism. Nitric Oxide 63 21-28. (doi:10.1016/j. niox.2016.12.007)

Gereben B, Zavacki AM, Ribich S, Kim BW, Huang SA, Simonides WS, Zeöld A \& Bianco AC 2008 Cellular and molecular basis of deiodinaseregulated thyroid hormone signaling. Endocrine Reviews 29 898-938. (doi:10.1210/er.2008-0019)

Hapon MB, Simoncini M, Via G \& Jahn GA 2003 Effect of hypothyroidism on hormone profiles in virgin, pregnant and lactating rats, and on lactation. Reproduction 126 371-382. (doi:10.1530/rep.0.1260371)

Hapon MB, Varas SM, Jahn GA \& Giménez MS 2005 Effects of hypothyroidism on mammary and liver lipid metabolism in virgin and late-pregnant rats. Journal of Lipid Research 46 1320-1330. (doi:10.1194/jlr.M400325-JLR200)

Hapon MB, Motta AB, Ezquer M, Bonafede M \& Jahn GA 2007 Hypothyroidism prolongs corpus luteum function in the pregnant rat. Reproduction 133 197-205. (doi:10.1530/REP-06-0035)

Hiroi Y, Kim H-H, Ying H, Furuya F, Huang Z, Simoncini T, Noma K, Ueki K, Nguyen N-H, Scanlan TS, et al. 2006 Rapid nongenomic actions of thyroid hormone. PNAS 103 14104-14109. (doi:10.1073/ pnas.0601600103)

Iervasi G \& Nicolini G 2013 Thyroid hormone and cardiovascular system: from basic concepts to clinical application. Internal and Emergency Medicine 8 (Supplement 1) S71-S74. (doi:10.1007/s11739-013-0911-4)

Jeddi S, Zaman J \& Ghasemi A 2015 Effects of ischemic postconditioning on the hemodynamic parameters and heart nitric oxide levels of hypothyroid rats. Arquivos Brasileiros de Cardiologia 104 136-143. (doi:10.5935/abc.20140181)

Makino A, Wang H, Scott BT, Yuan JX-J \& Dillmann WH 2012 Thyroid hormone receptor- $\alpha$ and vascular function. American Journal of Physiology: Cell Physiology 302 C1346-C1352. (doi:10.1152/ ajpcell.00292.2011)

Mallela MK, Strobl M, Poulsen RR, Wendler CC, Booth CJ \& Rivkees SA 2014 Evaluation of developmental toxicity of propylthiouracil and methimazole. Birth Defects Research Part B 101 300-307. (doi:10.1002/ bdrb.21113)

McAllister RM, Albarracin I, Price EM, Smith TK, Turk JR \& Wyatt KD 2005 Thyroid status and nitric oxide in rat arterial vessels. Journal of Endocrinology 185 111-119. (doi:10.1677/joe.1.06022)

Mochalov SV, Kalenchuk VU, Gaĭnullina DK, Vorotnikov AV \& Tarasova OS 2008 The contribution of protein kinase $\mathrm{C}$ and Rho-kinase to the control of the receptor-dependent artery contraction decreases with age independently of sympathetic innervation. Biophysics $\mathbf{5 3} 626$. (doi:10.1134/S0006350908060298)

Morikage N, Kishi H, Sato M, Guo F, Shirao S, Yano T, Soma M, Hamano K, Esato K \& Kobayashi S 2006 Cholesterol primes vascular smooth muscle to induce $\mathrm{Ca} 2$ sensitization mediated by a sphingosylphosphorylcholine-Rho-kinase pathway: possible role for membrane raft. Circulation Research 99 299-306. (doi:10.1161/01. RES.0000235877.33682.e9)

Mortimer RH, Cannell GR, Addison RS, Johnson LP, Roberts MS \& Bernus I 1997 Methimazole and propylthiouracil equally cross the perfused human term placental lobule. Journal of Clinical Endocrinology and Metabolism 82 3099-3102. (doi:10.1210/jcem.82.9.4210)
Mullur R, Liu Y-Y \& Brent GA 2014 Thyroid hormone regulation of metabolism. Physiological Reviews 94 355-382. (doi:10.1152/ physrev.00030.2013)

Mulvany MJ \& Halpern W 1977 Contractile properties of small arterial resistance vessels in spontaneously hypertensive and normotensive rats. Circulation Research 41 19-26. (doi:10.1161/01.RES.41.1.19)

Nagao H, Sasaki M, Imazu T, Takahashi K, Aoki H \& Minato K 2014 Effects of triiodothyronine on turnover rate and metabolizing enzymes for thyroxine in thyroidectomized rats. Life Sciences $\mathbf{1 1 6}$ 74-82. (doi:10.1016/j.lfs.2014.09.016)

Nishimura J, Bi D \& Kanaide H 2006 Dependence of proliferating dedifferentiated vascular smooth muscle contraction on RhoRho kinase system. Trends in Cardiovascular Medicine 16 124-128. (doi:10.1016/j.tcm.2006.02.004)

Obradovic M, Gluvic Z, Sudar-Milovanovic E, Panic A, Trebaljevac J, Bajic V, Zarkovic M \& Isenovic ER 2016 Nitric oxide as a marker for levo-thyroxine therapy in subclinical hypothyroid patients. Current Vascular Pharmacology 14 266-270. (doi:10.2174/1570161114666160 208143537)

Ohashi Y, Kawashima S, Hirata KI, Yamashita T, Ishida T, Inoue N, Sakoda T, Kurihara H, Yazaki Y \& Yokoyama M 1998 Hypotension and reduced nitric oxide-elicited vasorelaxation in transgenic mice overexpressing endothelial nitric oxide synthase. Journal of Clinical Investigation 102 2061-2071. (doi:10.1172/JCI4394)

Ojamaa K 2010 Signaling mechanisms in thyroid hormone-induced cardiac hypertrophy. Vascular Pharmacology 52 113-119. (doi:10.1016/j.vph.2009.11.008)

Owens GK, Kumar MS \& Wamhoff BR 2004 Molecular regulation of vascular smooth muscle cell differentiation in development and disease. Physiological Reviews 84 767-801. (doi:10.1152/ physrev.00041.2003)

Platts SH, Martinez-Lemus LA \& Meininger GA 2002 Microtubuledependent regulation of vasomotor tone requires Rho-kinase. Journal of Vascular Research 39 173-182. (doi:57765)

Portman MA 2008 Thyroid hormone regulation of perinatal cardiovascular function. Seminars in Perinatology 32 419-422. (doi:10.1053/j.semperi.2008.09.007)

Portman MA, Xiao Y, Qian K, Tucker RL, Parish SM \& Ning XH 2000 Thyroid hormone coordinates respiratory control maturation and adenine nucleotide translocator expression in heart in vivo. Circulation 102 1323-1329. (doi:10.1161/01.CIR.102.11.1323)

Puzdrova VA, Kudryashova TV, Gaynullina DK, Mochalov SV, Aalkjaer C, Nilsson H, Vorotnikov AV, Schubert R \& Tarasova OS 2014 Trophic action of sympathetic nerves reduces arterial smooth muscle $\mathrm{Ca}(2+)$ sensitivity during early post-natal development in rats. Acta Physiologica 212 128-141. (doi:10.1111/apha.12331)

Reho JJ, Zheng X, Benjamin JE \& Fisher SA 2014 Neural programming of mesenteric and renal arteries. American Journal of Physiology: Heart and Circulatory Physiology. (doi:10.1152/ajpheart.00250.2014)

Sánchez-García O, Rodríguez-Castelán J, Martínez-Gómez M, Cuevas E \& Castelán F 2015 Hypothyroidism modifies morphometry and thyroidhormone receptor expression in periurethral muscles of female rabbits. Neurourology and Urodynamics 35 895-901. (doi:10.1002/ nau.22842)

Sandoval RJ, Injeti ER, Gerthoffer WT \& Pearce WJ 2007 Postnatal maturation modulates relationships among cytosolic $\mathrm{Ca} 2+$, myosin light chain phosphorylation, and contractile tone in ovine cerebral arteries. American Journal of Physiology: Heart and Circulatory Physiology 293 H2183-H2192. (doi:10.1152/ajpheart.00647.2007)

Savinova OV, Liu Y, Aasen GA, Mao K, Weltman NY, Nedich BL, Liang Q \& Gerdes AM 2011 Thyroid hormone promotes remodeling of coronary resistance vessels. PLOS ONE 6 e25054. (doi:10.1371/journal. pone.0025054)

Sharlin DS, Gilbert ME, Taylor MA, Ferguson DC \& Zoeller RT 2010 The nature of the compensatory response to low thyroid hormone http://joe.endocrinology-journals.org

DOI: $10.1530 / \mathrm{JOE}-17-0225$
(C) 2017 Society for Endocrinology Printed in Great Britain
Published by Bioscientifica Ltd 
in the developing brain. Journal of Neuroendocrinology 22 153-165. (doi:10.1111/j.1365-2826.2009.01947.x)

Shibutani M, Woo G-H, Fujimoto H, Saegusa Y, Takahashi M, Inoue K, Hirose M \& Nishikawa A 2009 Assessment of developmental effects of hypothyroidism in rats from in utero and lactation exposure to antithyroid agents. Reproductive Toxicology 28 297-307. (doi:10.1016/j. reprotox.2009.04.011)

Shimokawa H, Sunamura S \& Satoh K 2016 RhoA/rho-kinase in the cardiovascular system. Circulation Research 118 352-366. (doi:10.1161/CIRCRESAHA.115.306532)

Silva JF, Vidigal PN, Galvão DD, Boeloni JN, Nunes PP, Ocarino NM, Nascimento EF \& Serakides R 2012 Fetal growth restriction in hypothyroidism is associated with changes in proliferative activity, apoptosis and vascularisation of the placenta. Reproduction, Fertility, and Development 24 923-931. (doi:10.1071/RD11219)

Sofronova SI, Gaynullina DK, Martyanov AA \& Tarasova OS 2015 Endogenous oestrogens do not regulate endothelial nitric oxide production in early postnatal rats. European Journal of Pharmacology 765 598-605. (doi:10.1016/j.ejphar.2015.09.037)

Sofronova SI, Borzykh AA, Gaynullina DK, Kuzmin IV, Shvetsova AA, Lukoshkova EV \& Tarasova OS 2016 Endothelial nitric oxide weakens arterial contractile responses and reduces blood pressure during early postnatal development in rats. Nitric Oxide 55-56 1-9. (doi:10.1016/j. niox.2016.02.005)

Somlyo AP \& Somlyo AV 2003 Ca2+ sensitivity of smooth muscle and nonmuscle myosin II: modulated by $\mathrm{G}$ proteins, kinases, and myosin phosphatase. Physiological Reviews 83 1325-1358. (doi:10.1152/ physrev.00023.2003)

Stagnaro-Green A 2015 Postpartum Management of Women Begun on Levothyroxine during Pregnancy. Frontiers in Endocrinology 6183. (doi:10.3389/fendo.2015.00183)
Suzuki M \& O'Neal RM 1967 Effects of therapeutic and toxic doses of propylthiouracil in rats. Journal of Pharmacology and Experimental Therapeutics 155 345-351.

Taylor MA, Swant J, Wagner JJ, Fisher JW \& Ferguson DC 2008 Lower thyroid compensatory reserve of rat pups after maternal hypothyroidism: correlation of thyroid, hepatic, and cerebrocortical biomarkers with hippocampal neurophysiology. Endocrinology 149 3521-3530. (doi:10.1210/en.2008-0020)

Tian L, Ni J, Guo T, Liu J, Dang Y, Guo Q \& Zhang L 2014 TSH stimulates the proliferation of vascular smooth muscle cells. Endocrine $\mathbf{4 6}$ 651-658. (doi:10.1007/s12020-013-0135-4)

Vallot O, Combettes L, Jourdon P, Inamo J, Marty I, Claret M \& Lompré AM 2000 Intracellular $\mathrm{Ca}(2+)$ handling in vascular smooth muscle cells is affected by proliferation. Arteriosclerosis, Thrombosis, and Vascular Biology 20 1225-1235. (doi:10.1161/01.ATV.20.5.1225)

Vargas F, Moreno JM, Rodríguez-Gómez I, Wangensteen R, Osuna A, Alvarez-Guerra M \& García-Estañ J 2006 Vascular and renal function in experimental thyroid disorders. European Journal of Endocrinology 154 197-212. (doi:10.1530/eje.1.02093)

Warner A, Rahman A, Solsjö P, Gottschling K, Davis B, Vennström B, Arner A \& Mittag J 2013 Inappropriate heat dissipation ignites brown fat thermogenesis in mice with a mutant thyroid hormone receptor $\alpha 1$. PNAS 110 16241-16246. (doi:10.1073/pnas.1310300110)

Wei W, Wang Y, Wang Y, Dong J, Min H, Song B, Teng W, Xi Q \& Chen J 2013 Developmental hypothyroxinaemia induced by maternal mild iodine deficiency delays hippocampal axonal growth in the rat offspring. Journal of Neuroendocrinology 25 852-862. (doi:10.1111/jne.12058)

Yasuzawa-Amano S, Toyoda N, Maeda A, Kosaki A, Mori Y, Iwasaka T \& Nishikawa M 2004 Expression and regulation of type 2 iodothyronine deiodinase in rat aorta media. Endocrinology 145 5638-5645. (doi:10.1210/en.2004-0632)

Received in final form 7 August 2017

Accepted 9 August 2017

Accepted Preprint published online 9 August 2017
๑) 2017 Society for Endocrinology Printed in Great Britain 